"Fl suleer ile mis hiips

Año 13.

Núm. 33

https://revistainvestigacionacademicasinfrontera.unison.mx/index.php/RDIASF
Revista de Investigación

Académica sin Frontera

ISSN: 2007-8870

Recibido el 27 de mayo de 2020. Dictaminado mediante arbitraje favorablemente 22 de diciembre de 2020.

\title{
Confiabilidad de un instrumento para medir la relación de las competencias y la diversidad en el desarrollo directivo del sector PyME del giro restaurantero de Ciudad Obregón, Sonora, México.
}

Dra. Lizeth Alejandra González Martínez - Universidad Estatal de Sonora

ORCID 0000-0001-9403-1534 - https://orcid.org/0000-0001-9403-1534

Dr. Daniel Paredes Zempual - Universidad Estatal de Sonora

ORCID 0000-0002-3688-2565 - https://orcid.org/0000-0002-3688-2565

L.A. Obdulia Ana Bucio Rodríguez - Universidad Estatal de Sonora

ORCID 0000-0002-2433-8941 - https://orcid.org/0000-0002-2433-8941

\section{Resumen}

La presente investigación muestra los resultados obtenidos de la aplicación de una prueba piloto para observar el comportamiento del instrumento y establecer el grado de confiabilidad por medio del análisis en el software estadístico SPSS. Dicho cuestionario mide la incidencia de las competencias directivas y la diversidad en el desarrollo directivo de las pequeñas y medianas empresas (PyMEs) del giro restaurantes ubicadas en la ciudad de Obregón, Sonora, México. Dentro del estudio se analizaron dos variables independientes denominadas competencias directivas y diversidad, en relación con la variable dependiente desarrollo directivo. El trabajo se llevó a cabo con los directivos de las PyMEs, las cuales representan el eje central de la economía del país y tiene por objetivo específico determinar el grado de vinculación que tienen las habilidades del capital humano con respecto al desarrollo directivo. Para este estudio se aplicaron 50 cuestionarios con el fin de comprobar la efectividad del instrumento y así a futuro generar a través de los resultados las conclusiones que permitan proponer recomendaciones a los gerentes para contribuir en su desarrollo directivo que le facilite dirigir eficientemente y productivamente las empresas.

Palabras claves: Habilidades del capital Humano, Desarrollo directivo y PyMEs.

\begin{abstract}
This research shows the results obtained from the application of a pilot test to observe the behavior of the instrument and establish the degree of reliability through the analysis in the SPSS statistical software. This questionnaire measures the incidence of managerial competencies and diversity in the managerial development of small and medium-sized companies (SMEs) of the restaurant business located in Obregon city, Sonora, México. In the study two independent variables called
\end{abstract}


mFl siber ide mis hiins hard mi prondersi"

Año 13.

Núm. 33

https://revistainvestigacionacademicasinfrontera.unison.mx/index.php/RDIASF

Revista de Investigación

Académica sin Frontera

ISSN: 2007-8870

Recibido el 27 de mayo de 2020. Dictaminado mediante arbitraje favorablemente 22 de diciembre de 2020.

management skills and diversity in connection with the development manager dependent variable analyzed. The work was conducted with managers of SMEs, which represent the backbone of the economy in the country and specifically aims to determine the degree of linkage with the skills of human capital with respect to management development. For this study 50 questionnaires were applied in order to test the effectiveness of the instrument and thus future generated through the results conclusions that allow propose recommendations to managers to assist in their management development to facilitate direct you to efficiently and productively companies.

Keywords: Human capital skills, Management development and SMEs.

\section{Introducción}

Las pequeñas y medianas empresas (PyMEs) han sido a lo largo de la historia grandes generadoras de empleo, riqueza y nuevas ideas, gracias a sus características que les permiten ser flexibles en sus procesos de producción y adaptarse a las necesidades del entorno. Actualmente estas entidades son reconocidas como un excelente medio para impulsar el desarrollo económico de todos los países (Comisión Económica para América Latina, [CEPAL], 2009).

Por lo antes mencionado la OIT, reconoce y afirma que las PyMEs en conjunto con las MiPyMEs son generadoras del 70\% de los del total de empleos, motivo por el cual los países han focalizado sus esfuerzos en crear programas y estrategias diseñadas para apoyar el sostenimiento

y desarrollo de estas unidades económicas, de igual manera se ha despertado un gran interés por el estudio minucioso de las formas de gestión y sus características particulares (Organización Internacional del Trabajo [OIT], 2019).

Actualmente en América Latina el 99\% de los establecimientos son MiPyMEs y aunque la generación de empleo es alta, su aportación al PIB sigue siendo baja y la apertura comercial a ha contribuido además a un alto índice de fracaso. 
Año 13.

Núm. 33

ISSN: 2007-8870

https://revistainvestigacionacademicasinfrontera.unison.mx/index.php/RDIASF

Recibido el 27 de mayo de 2020. Dictaminado mediante arbitraje favorablemente 22 de diciembre de 2020.

Dentro de este contexto, México no es la excepción pues, aunque estas empresas son uno de los pilares financieros de la nación su desarrollo es lento y difícilmente logran el éxito. Lo anterior, sustenta la motivación de llevar a cabo la presente investigación, que tiene como objetivo determinar la confiabilidad de un instrumento que permite medir la relación entre las Habilidades del capital humano y el Desarrollo directivo específicamente de las PyMEs dedicadas al sector servicio en el giro de restaurantes.

Por último, se pretende establecer un instrumento de medición que permita en un futuro definir y conceptualizar el Desarrollo directivo en las PyMEs, puesto que varios autores coinciden en que no es sencillo definir este concepto, sin embargo, proponen que se deben contar con mecanismos agiles y eficaces para desarrollar las capacidades de los líderes que demanda el entorno para una verdadera ventaja competitiva.

\section{Antecedentes}

En la actualidad se vive rodeado de todo tipo de empresas que son de interés por razones diferentes, ya sea por su tipo productivo, por su interés financiero o por sus relaciones contractuales, todas estas razones son las que consideran a la empresa como una realidad socio-económica a estudiar dentro del ámbito de las ciencias, y en particular dentro de la economía. Por su parte Gill (2009) define al término empresa como un conjunto de medios humanos y materiales que se disponen para conseguir una finalidad según un esquema determinado de relaciones y dependencias entre los diferentes elementos que la componen.

De acuerdo con la revista Forbes (2018) basada en datos oficiales, en México existen 4.2 millones de unidades económicas. De ese universo, el 99.8\% son consideradas Micro, Pequeñas y Medianas Empresas (MiPyMEs), las cuales aportan 42\% del Producto Interno Bruto (PIB) y generan el 70\% del empleo en el país. Las PyMEs, ante la dinámica del nuevo escenario de la economía global, tienen el reto de renovar su diseño empresarial en pos de la eficiencia, puesto 
"Fl silwer ile mis hijics

Año 13.

Núm. 33

https://revistainvestigacionacademicasinfrontera.unison.mx/index.php/RDIASF
Revista de Investigación

Académica sin Frontera

ISSN: 2007-8870

Recibido el 27 de mayo de 2020. Dictaminado mediante arbitraje favorablemente 22 de diciembre de 2020.

que, para ofrecer productos de alta calidad y con mayor valor agregado, deben internamente incrementar su productividad, rentabilidad y coadyuvar en el mejoramiento de la calidad de vida de sus trabajadores logrando competir de manera exitosa, sólo las más eficientes y las que se adecúan a las exigencias del mercado (Cardozo, De Naime y Monroy, 2012).

Según La Ley para el Desarrollo de la Competitividad de la MiPyME (2019) señala que las empresas se clasifican de la siguiente manera:

Tabla 1. Clasificación de las empresas.

\begin{tabular}{llll}
\hline Tamaño & Industria & Comercio & Servicio \\
\hline Micro & $0-10$ & $0-10$ & $0-10$ \\
Pequeña & $11-50$ & $11-30$ & $11-50$ \\
Mediana & $51-250$ & $31-100$ & $51-100$ \\
Grande & 251 o más & 101 o más & 101 o más \\
\hline Fuente: Ley para el Desarrollo de la Competitividad de la Micro, Pequeña y Mediana Empresa.
\end{tabular}

Las PyMEs del sector servicios es uno de los tres grandes sectores en los que se dividen las actividades económicas. Según la revista Forbes (2018), de las 4.2 millones de unidades económicas que existen en México, el 99.8\% son pequeñas y medianas empresas (PyMEs), que conforman su plantilla laboral de entre uno y 100 trabajadores, de las cuales el $53 \%$ se dedican al comercio, $35 \%$ a los servicios y el $12 \%$ a la industria.

El INEGI (2019) establece que los servicios de hoteles y restaurantes, ocupan la mayor parte de empresas en el segmento de servicios, convirtiéndose este sector, en uno de los más importantes en las economías avanzadas, tanto en términos de producción como en el volumen de empleo, con un incremento notable desde los años 70 a nivel mundial. 
"Fl silwer ile mis hijics

Año 13.

Núm. 33

https.//revis

Recibido el 27 de mayo de 2020. Dictaminado mediante arbitraje favorablemente 22 de diciembre de 2020.

A nivel internacional las PyMEs representan una de las principales fuerzas en el desarrollo económico, de cualquier país en transición. La ONU (2018) considera que las PyMEs son la espina dorsal de la economía y las mayores empleadoras del mundo. Este organismo ha señalado que, según los datos del Consejo Internacional para la pequeña empresa, este tipo de negocios representan más del $90 \%$ del total de empresas, generando entre el $60 \%$ y el $70 \%$ del empleo y son responsables del 50\% del Producto Interior Bruto a nivel mundial. El autor Ávila (2014) a partir de su estudio acerca de la competitividad de las PyMEs en México, menciona que son consideradas como lucha contra la pobreza que se vive actualmente en el país. Así mismo, expone que existen obstáculos que retrasan su crecimiento, como lo son el uso de la tecnología; una herramienta que ha hecho evolucionar el mundo y hacerlo globalizado.

Sin embargo, uno de los problemas más graves de las PyMEs en México es que no realizan actividades de investigación y desarrollo, su estructura organizacional no es flexible y no les favorece para lograr sus objetivos como empresa, además de no contar con capacidad para identificar problemas para el mejoramiento que les ayude a ser más competitivas.

Las PyMEs en Sonora de acuerdo con la Secretaría de Economía de Sonora (2019), impactan en la economía del estado, produciendo el $80 \%$ de los empleos que se generan. Siendo actualmente el sector restaurante uno de los más importantes del estado, existiendo poco más de 9,685 restaurantes a nivel estatal y a nivel nacional más de 515 mil, cifra que representa el 10.6 por ciento de las unidades económicas nacionales y emplea al 6.6 por ciento del personal ocupado del país, que son un millón 433 mil personas. Hoy en día, este sector deja 1.4 por ciento del PIB nacional y el 13 por ciento del PIB turístico, con un crecimiento dinámico de un 3.7 por ciento con ventas mayores a 180 mil millones de pesos.

Pero a su vez, la mortandad de estas PyMEs es muy elevada, ya sea por la falta de financiamiento, por la falta de preparación, por la falta de capacitación o por la falta de recursos (CANIRAC, 2011). 
Año 13.

Núm. 33

ISSN: 2007-8870

https://revistainvestigacionacademicasinfrontera.unison.mx/index.php/RDIASF

Recibido el 27 de mayo de 2020. Dictaminado mediante arbitraje favorablemente 22 de diciembre de 2020.

Por su parte, Díaz (2017) señala que el $60 \%$ de las pequeñas y medianas empresas en Sonora fracasan y cierran a los años de haber nacido. Cifra realmente preocupante, dado que se consideran la principal fuente de empleo del Estado.

En Ciudad Obregón, de acuerdo con un estudio realizado por Torres, Wendlandt y López (2016) acerca de la formalización administrativa de las PyMEs de la industria alimentaria de Ciudad Obregón, concluyeron que por lo general son negocios familiares, lo que implica que la mayoría de las veces no se lleve a cabo una planeación bien estructurada y con el tiempo adecuado, siendo la prioridad principal para las personas que las dirigen la obtención de ingresos de manera rápida, lo cual impacta de manera significativa en su consolidación.

Con relación a lo antes mencionado, las ventajas competitivas de las PyMEs según Estrella, Jiménez, Ruiz y Sánchez (2012) se desprenden de la competitividad, misma que se basa en sus fortalezas internas y su interacción con los factores externos, y esta se alcanza cuando se cuenta con recursos, habilidades únicas y con estrategias de negocio superiores a las de sus directos rivales. Estas ventajas competitivas pueden tener su origen en diversos aspectos, como el uso de la tecnología, la gestión del conocimiento, análisis de los costos y la especialización.

Para finalizar, una PyME que desee contar con una Compoetividad efectiva en los mercados debe de contar con un Directivo desarrollado, ya que el directivo juega un papel protagónico en la orientación de la empresa ya sea capaz de llevarla al éxito o al fracaso, dado que a través de las habilidades que posee puede mejorar, actualizar, desarrollar y potencializar a la organización.

Pérez y Serrano (2013) señalan que, para avanzar y crecer la llave del éxito es contar con los recursos humanos necesarios, en especial en los puestos directivos en los que se adoptan las decisiones de las que depende la orientación, especialización y productividad de las empresas. Así mismo, López (2017) expone que el contar con directivos desarrollados es una clave para lograr el éxito de las empresas. Sin embargo, acorde con Chiavenato (2011), el componente estratégico más importante es la calidad del talento humano que trabaja en la organización. 
"Fl silwer ile mis hijics

Año 13.

Núm. 33
Revista de Investigación

Académica sin Frontera

ISSN: 2007-8870 https://revistainvestigacionacademicasinfrontera.unison.mx/index.php/RDIASF

Recibido el 27 de mayo de 2020. Dictaminado mediante arbitraje favorablemente 22 de diciembre de 2020.

En este contexto, es muy importante que las organizaciones focalicen sus esfuerzos en el desarrollo de las competencias del talento humano, y con mayor énfasis en los directivos, dado que gran parte del desempeño de una organización depende de ellos.

\section{Objetivo general de la investigación}

Determinar la confiabilidad de un instrumento para medir la relación de las competencias y la diversidad en el desarrollo directivo del sector PyME del giro restaurantero de Ciudad Obregón, Sonora, México.

\section{Unidad de análisis}

El estudio se centra en aplicar el instrumento para medir su confiabilidad a 50 directivos, gerentes, supervisores o coordinadores de las PyMEs dedicadas a preparar y servir alimentos, localizadas en Ciudad Obregón, Sonora, México, como se muestra en la Figura siguiente, la cual tiene una importante industria de servicios y de producción de alimentos a nivel estatal. En Sonora, actualmente existen 9,685 PyMEs del giro restaurantero. 
"Fl suber ise mis hijos

Año 13.

Núm. 33

https://revistainvestigacionacademicasinfrontera.unison.mx/index.php/RDIASF

Revista de Investigación

Académica sin Frontera

ISSN: 2007-8870

Recibido el 27 de mayo de 2020. Dictaminado mediante arbitraje favorablemente 22 de diciembre de 2020.

Figura 1. Mapa del estado de Sonora donde se localiza la unidad de análisis.

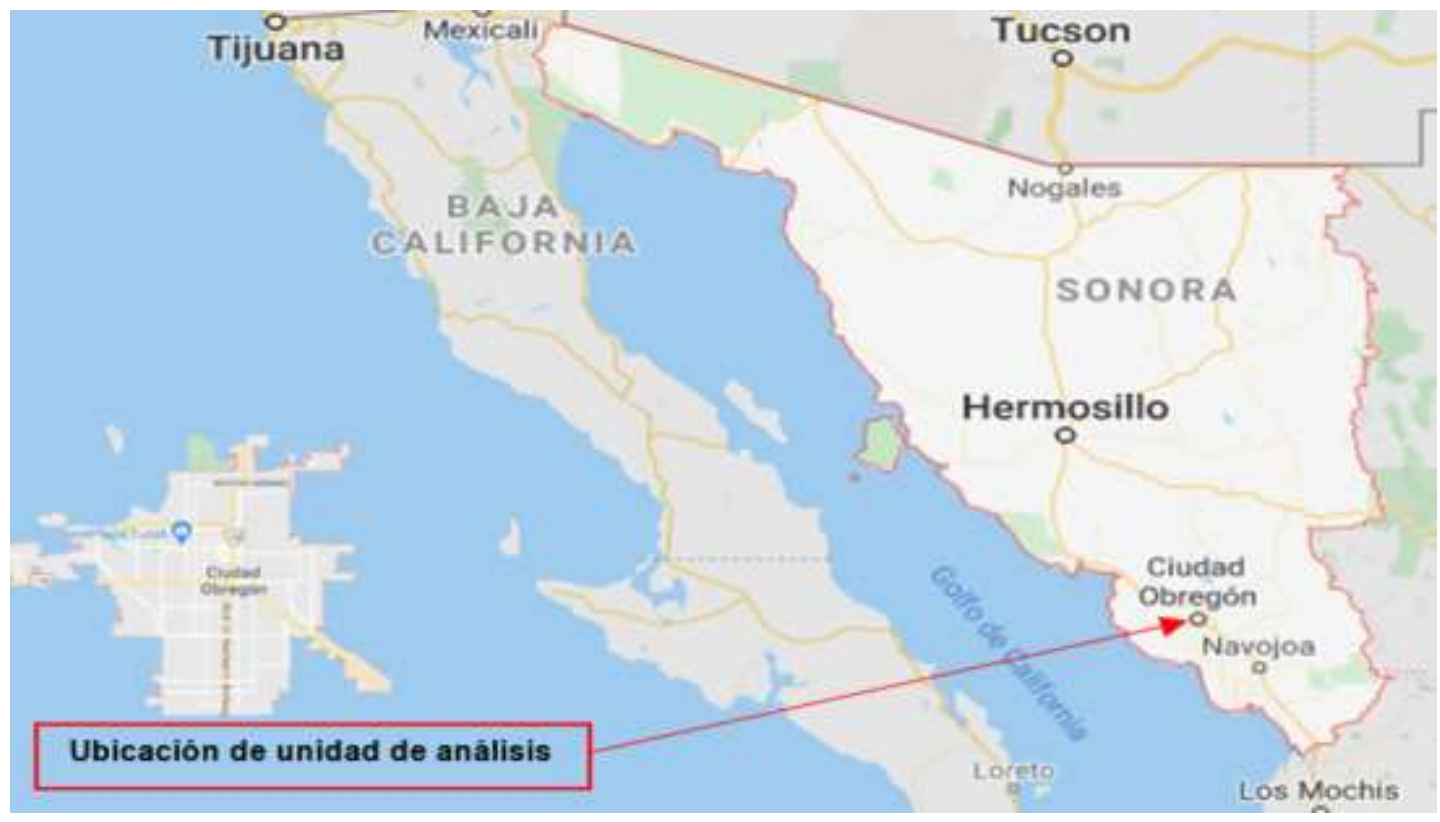

Fuente: https://www.mexicodesconocido.com.mx/mapa-de-sonora.html.

\section{Marco teórico}

\section{Antecedentes teóricos generales}

Sin duda alguna, uno de los factores de éxito tanto de las pequeñas, medianas y grandes empresas que permiten su crecimiento y un eficiente comportamiento en el mercado que es cada vez más competitivo, es la preparación y las capacidades que poseen las personas que las dirigen. Es por eso que la función directiva en la empresa es un factor crítico para el logro de los objetivos, el crecimiento y el desarrollo integral de la organización. 
"Fl silwer ile mis hijics

Año 13.

Núm. 33

https://revis
Revista de Investigación

Académica sin Frontera

ISSN: 2007-8870

Recibido el 27 de mayo de 2020. Dictaminado mediante arbitraje favorablemente 22 de diciembre de 2020.

Cuervo (2004) hace mención que los directivos son las personas de la organización que planifican, organizan, dirigen y controlan las tareas que se realizan en ella, y que, además de asignar

y coordinar el conjunto de factores productivos de que dispone la empresa, estos deben ocuparse de la generación de nuevos recursos y mejorar los ya existentes, de lo cual depende que la empresa pueda crecer, expandirse o bien, mantenerse el mercado. López y Molina (2014) determinan que el desarrollo directivo es el nuevo elemento en la ecuación del éxito, que empieza a ser introducido de manera sistemática en la teoría económica, puesto que sus decisiones y acciones son las que constituyen la diferencia entre las empresas que permanecen, las que crecen y las que se estancan o mueren.

\section{Desarrollo directivo}

Según el Diccionario empresarial (2008), el Desarrollo directivo es un proceso formativo encaminado a desarrollar profesionalmente a una persona, como evolución de su carrera dentro de una empresa, con el objetivo de aumentar su eficiencia en el desempeño de sus funciones directivas.

Por otro lado, de acuerdo con De Haro (2011) dentro de su estudio acerca del Desarrollo directivo menciona que este no es un concepto fácil de definir, puesto que los diferentes modos de entender y conceptualizar el liderazgo dificultan la tarea de delimitar su objeto de estudio. En base a lo antes mencionado, Puga y Martínez (2008) señalan que las decisiones que toman los directivos del nivel superior impactan en el funcionamiento total de la organización que dirigen y guardan estrecha conexión con los conocimientos y creencias que ellos han cultivado a lo largo del tiempo.

De la misma manera Patrón y Barroso (2015) exponen que, en gran parte el desempeño eficaz y eficiente de una organización comienza por la habilidad de sus gerentes para organizar, dirigir, comunicarse y motivar a su personal. Por su parte Ramírez (2016) menciona en su informe 
Año 13.

Núm. 33

ISSN: 2007-8870

https://revistainvestigacionacademicasinfrontera.unison.mx/index.php/RDIASF

Recibido el 27 de mayo de 2020. Dictaminado mediante arbitraje favorablemente 22 de diciembre de 2020.

de gestión, que es habitual encontrarse con directivos que ejercen como buenamente pueden, llevando a cabo este rol de manera casi intuitiva.

\section{Habilidades del capital humano}

De acuerdo con Serrano (2017) todo directivo requiere de conocimientos técnicos relacionados con el campo en el que se desenvuelve su negocio, tanto los que tienen que ver con los procesos productivos como los que de una u otra manera puedan afectar la marcha de la empresa. Al igual, Lorenzana (2020) expone que la persona a cargo de cualquier organización debe saber motivar, inspirar y transmitir valores al equipo de trabajo para que todo funcione como un reloj. Sin lugar a dudas el éxito de cualquier organización se vincula estrechamente al desempeño de todas las personas que la integran, sin importar su jerarquía, ubicación y condición, pues son ellas las que poseen habilidades, conocimientos, relaciones sociales, actitudes, valores y son ellas las que deciden dónde, cuándo y cómo utilizarlos (Valencia, 2005).

Por su parte, Mertens (2001) señala que el desarrollo de habilidades del capital humano ha tomado una posición importante, en relación a las capacidades de un trabajador para movilizar los conocimientos, las habilidades y las actitudes necesarias para alcanzar los resultados pretendidos en un determinado contexto profesional.

Además, las habilidades gerenciales están unidas a factores simbólicos como habilidades de comunicación, capacidad de adaptación, receptividad a los ambientes exteriores, fuertes habilidades técnicas, manejo del estrés, capacidad de trabajar bien con otros, inteligencia social y valoración de la diversidad multicultural y trabajo en equipo para que influyan positivamente en

una gestión enfocada a la competitividad empresarial (Leyva, Cavazos y Espejel, 2018). Por otro lado, Estrada, García, y Sánchez (2009) en su estudio respecto a los factores internos determinantes de la competitividad en México, concluyó que las PyMEs altamente competitivas son aquellas en 
"Fl suber ise mis hijos

Año 13.

Núm. 33

https://revistainvestigacionacademicasinfrontera.unison.mx/index.php/RDIASF
Revista de Investigación

Académica sin Frontera

ISSN: 2007-8870

Recibido el 27 de mayo de 2020. Dictaminado mediante arbitraje favorablemente 22 de diciembre de 2020.

las que sus directivos innovan en sus productos y procesos, que tienen un nivel tecnológico superior y poseen una planeación estratégica en su gestión empresarial.

\section{Competencias directivas}

De acuerdo con Chinchilla y García (2001) las competencias directivas son aquellos comportamientos observables y habituales que permiten alcanzar el éxito de una persona en la función directiva. Por su parte el Instituto Tecnológico y de Estudios Superiores de Monterrey (2009) definen a las competencias directivas como el conjunto de conocimientos, creencias, capacidades, habilidades, actitudes, valores y estrategias que posee un director y que determina el modo y los resultados de sus intervenciones.

Por su parte Elizondo, Armenteros y Molina (2014) a partir de su estudio acerca de las competencias directivas para PyMEs, señalan que estas competencias permiten una administración y gestión más efectiva que impacta al talento organizacional y el desempeño empresarial. Así mismo, Ramírez, Cerón, y Maya (2017) señalan que una organización donde se promueve el desarrollo y mejoramiento de las competencias directivas, se genera como consecuencia el que se implementen de manera continua una serie de estrategias novedosas y efectivas, encaminadas a mantener a la empresa en un nivel competitivo dentro de su sector.

Así mismo, Peña (2015) hace hincapié que la motivación juega un papel crucial en la gestión de personas. Para que un individuo realice una tarea deben concurrir tres requisitos: que el individuo pueda hacerlo (medios), que tenga conocimientos para hacerlo (habilidades y aptitudes) y que quiera hacerlo (motivación). Para poseer la clave del comportamiento humano es necesario poseer la clave de la motivación. 
Año 13.

Núm. 33

ISSN: 2007-8870

https://revistainvestigacionacademicasinfrontera.unison.mx/index.php/RDIASF

Recibido el 27 de mayo de 2020. Dictaminado mediante arbitraje favorablemente 22 de diciembre de 2020.

\section{Diversidad.}

Actualmente la diversidad es considerada una ventaja competitiva, que integra culturas, estilos, destrezas, educación y diferentes formas de ver el mundo en una organización. Donde los principales propulsores de ella son los gerentes, quienes deben de reconocer las diferencias de sus colaboradores, de tal forma que aseguren su retención, generando una mayor productividad y una reducción en lo que respecta a la discriminación laboral. De acuerdo con Universia Colombia (2017) la diversidad e inclusión se trata de crear una cultura organizacional lo suficientemente fuerte para comprender las diferencias de cualquier tipo, con programas que aseguren el bienestar de los empleados, y donde exista un ambiente en el que la comunicación sea abierta y efectiva.

Por su parte, la Organización Internacional de Empleadores citado por Torres (2017) destaca que la discriminación basada en factores tales como el género, la raza o la discapacidad impide a las empresas disponer de las personas que necesitan para poder ser competitivas y adaptarse a las demandas del mercado. De acuerdo con la revista Forbes Advertorial (2018) la inclusión y la diversidad no sólo fomenta un ambiente más equitativo y aporta una visión global de las competencias corporativas, sino que también mejora la calidad de vida y aumenta los índices de productividad de las empresas. Sin embargo, este no es un cambio fácil para las organizaciones pues la misma estructura empresarial debe cambiar para poder ser incluyentes en todos sus ámbitos, y no únicamente hacia el género.

En este sentido, la variable diversidad utilizada de forma positiva incrementa la creatividad y la innovación en las organizaciones, así como también mejora la toma de decisiones ya que brinda diversas perspectivas sobre un problema. $\mathrm{Y}$ en los casos que no es bien administrada por los gerentes se puede presentar un alto grado de rotación, una difícil comunicación, así como una mayor cantidad de conflictos interpersonales, creando de esta manera un clima laboral poco saludable para sus colaboradores (Amoros, 2007). 
"Fl silwer ile mis hijics

Año 13.

Núm. 33

https://revistainvestigacionacademicasinfrontera.unison.mx/index.php/RDIASF
Revista de Investigación

Académica sin Frontera

ISSN: 2007-8870

Recibido el 27 de mayo de 2020. Dictaminado mediante arbitraje favorablemente 22 de diciembre de 2020.

\section{Estudios relacionados.}

En un estudio realizado por Pereda (2016), denominado análisis de las habilidades directivas, aplicado al sector público de la provincia de Córdoba en España, con el objetivo de establecer las competencias de dirección más requeridas en los trabajadores de la provincia de Córdoba, se obtuvo que las habilidades gerenciales que alcanzan una significación del 5\% son el liderazgo, la motivación, trabajo en equipo, colaboración, inteligencia emocional, gestión del estrés y asertividad. Mientras que habilidades gerenciales que alcanzaron el 10\% de significación fueron la capacidad de comunicación, resolución de conflicto y delegación de tareas.

Por otro lado, Anapan (2018) llevó a cabo una investigación acerca de las habilidades gerenciales y desarrollo organizacional, los resultados demostraron que entre las variables habilidades gerenciales y desarrollo organizacional existe una correlación de $r=0,381(p=0,011)$. Es decir que las habilidades gerenciales se relacionan directamente con el desarrollo organizacional.

En otra perspectiva un trabajo realizado por Elizondo Armenteros y Molina (2014) acerca de las competencias directivas para PyMEs del sector Servicios, en Saltillo, Coahuila, manifestó que las competencias directivas más desarrolladas de los dueños, gerentes y/o administradores son la gerencia de conflictos, desarrollo de la gente y la planeación; mientras que el trabajo en equipo, motivación y el seguimiento las más débiles.

En un estudio realizado por Patrón y Barroso (2015) en la ciudad de San Francisco Campeche, México, referente a las competencias directivas de gerentes de restaurantes turísticos, se encontró que las competencias que muestran mayor complejidad son del área del comportamiento humano, tales como formación de redes de relaciones efectivas, empatía, coaching, trabajo en equipo y desarrollo personal, entre otras. 
"Fl suber ise mis hijos

Año 13.

Núm. 33

https://revistainvestigacionacademicasinfrontera.unison.mx/index.php/RDIASF

Revista de Investigación

Académica sin Frontera

ISSN: 2007-8870

Recibido el 27 de mayo de 2020. Dictaminado mediante arbitraje favorablemente 22 de diciembre de 2020.

Por último, a través de un trabajo de investigación realizado por Puga y Martínez (2008) referente a las competencias directivas en escenarios globales se encontró que las competencias que necesitan poseer hoy los altos directivos para estar en armonía con los requerimientos del mundo empresarial actual, son; orientados al conocimiento, liderazgo, habilidad de comunicación, valores éticos y habilidad para trabajar en equipo. Competencias que resumen de alguna forma la relevancia de los comportamientos observables y habituales que justifican el éxito de una persona en su función directiva.

\section{Modelo gráfico de la investigación}

Con la investigación efectuada hasta la fecha, se propone un modelo gráfico que muestra la relación que existe entre las variables en estudio dentro de las PyMEs del giro restaurantes, tal como, las dos variables independientes denominadas habilidades del capital humano y la variable dependiente designada Desarrollo directivo, así como se muestra en la Tabla 2.

Tabla 2. Modelo gráfico propuesto.

\begin{tabular}{cc}
\hline $\begin{array}{c}\text { VARIABLES INDEPENDIENTES } \\
\text { (Causa) }\end{array}$ & $\begin{array}{c}\text { VARIABLE DEPENDIENTE } \\
\text { (Efecto) }\end{array}$ \\
Habilidades del Capital Humano & Desarrollo Directivo \\
\hline $\begin{array}{c}\mathrm{X}_{1}=\text { Competencias directivas } \\
\mathrm{X}_{2}=\text { Diversidad }\end{array}$ & $\mathrm{Y}=$ Desarrollo directivo \\
\hline \multicolumn{2}{c}{ Fuente: Elaboración propia. }
\end{tabular}

\section{Hipótesis.}

Es confiable el instrumento que mide las habilidades del capital humano con relación a las variables de Competencias directivas, la Diversidad y Desarrollo de los directivos de las PyMEs del giro restaurantes ubicadas en ciudad Obregón, Sonora, México. 
"Fl silwer ile mis hijics

Año 13.

Núm. 33
Revista de Investigación

Académica sin Frontera

ISSN: 2007-8870

https://revistainvestigacionacademicasinfrontera.unison.mx/index.php/RDIASF

Recibido el 27 de mayo de 2020. Dictaminado mediante arbitraje favorablemente 22 de diciembre de 2020.

\section{Material y método}

\section{Tipo de estudio}

La presente investigación se sustenta en el método científico, de tipo correlacional, que tiene como propósito medir el grado de relación que existe entre las variables independientes Competencias directivas y Diversidad y la variable dependiente Desarrollo directivo.

El enfoque de la investigación es cuantitativo puesto que, utiliza la recolección de datos para probar hipótesis con base en la medición numérica y el análisis estadístico (Hernández, 2014). También tiene un alcance exploratorio porque pretende establecer el estado actual de una situación, en este caso, se analizará un problema identificando conceptos de las variables.

Al mismo tiempo tiene un enfoque descriptivo porque a través de la observación directa, el análisis documental y la encuesta, se realiza una descripción de las variables. El diseño del estudio es no experimental, porque las variables no se manipulan y se realiza de manera transversal siendo que se estudia en un momento del tiempo, a una fecha determinada y con un diseño estructurado.

\section{Operacionalización de variables.}

De acuerdo con Apoyala (2012) la operacionalización de variables es el proceso de llevar una variable del nivel abstracto a un plano concreto y hacerla medible.

Es decir, que su proceso consiste en definir el concepto de la misma, determinar las dimensiones de la variable y la forma en que se medirá o validará mediante preguntas de una encuesta que se conforma por diversos constructos. 
Año 13.

Académica sin Frontera

Núm. 33

ISSN: 2007-8870

https://revistainvestigacionacademicasinfrontera.unison.mx/index.php/RDIASF

Recibido el 27 de mayo de 2020. Dictaminado mediante arbitraje favorablemente 22 de diciembre de 2020.

Tabla 3. Cuadro de operacionalización de variables.

\begin{tabular}{|c|c|}
\hline $\begin{array}{c}\text { Variables } \\
\text { independientes }\end{array}$ & Definición de la variable \\
\hline $\begin{array}{l}\text { Competencias } \\
\text { directivas }\end{array}$ & $\begin{array}{l}\text { De acuerdo con Chinchilla y García (2001) } \\
\text { las competencias directivas son aquellos } \\
\text { comportamientos observables y habituales } \\
\text { que permiten alcanzar el éxito de una } \\
\text { persona en la función directiva y una } \\
\text { administración y gestión más efectiva que } \\
\text { impacta al talento organizacional y el } \\
\text { desempeño empresarial. }\end{array}$ \\
\hline
\end{tabular}

1) Se realiza una planeación estratégica para el logro de metas de la empresa.

2) Se utiliza nueva tecnología para el logro de objetivos de la empresa.

3) Se forman equipos de trabajo que ayudan al logro de metas de la empresa.

4) Se tienen conocimientos y habilidades para desempeñar funciones de otras áreas de trabajo de la empresa.

5) Se realizan análisis estadísticos para conocer el desempeño laboral de los empleados.

6) Se evalúa de manera continua el desempeño del personal.

7) Las competencias administrativas que se han complementado contribuyen al desarrollo directivo.

Creado a partir de la revisión de literatura.

Actualmente la diversidad se considera una ventaja competitiva que se refiere a la creciente heterogeneidad de las organizaciones con la inclusión de diferentes grupos, en términos de raza, Diversidad género, edad, religión, estilo de vida, valores, apariencia física, estatus económico, discapacidad física o mental, nivel educativo, ideología política, personalidad y etnicidad, variable con la cual se trata de crear una cultura organizacional lo suficientemente fuerte para comprender las diferencias de cualquier tipo, con programas que aseguren el bienestar de los empleados, y donde exista un ambiente en el que la comunicación sea abierta y efectiva (Chinchilla y Cruz, 2011).

\author{
Variable \\ dependiente
}

8) El equipo de trabajo directivo está conformado igualmente por personal de ambos sexos.

9) En el equipo de trabajo colaboran personas de culturas diferentes.

10) Se toman en cuenta las diferentes ideas, creencias o formas de pensar del personal para la toma de decisiones.

11) Estaría dispuesto en contratar a personas con capacidades diferentes para desarrollar alguna actividad laboral dentro de la organización.

12) Hay convivencia sin problemas entre personal con diferentes creencias religiosas.

13) Hay un proceso de inclusión de personas en el trabajo que permite el desarrollo directivo.

Creado a partir de la revisión de literatura. 
Año 13.

Académica sin Frontera

Núm. 33

ISSN: 2007-8870

https://revistainvestigacionacademicasinfrontera.unison.mx/index.php/RDIASF

Recibido el 27 de mayo de 2020. Dictaminado mediante arbitraje favorablemente 22 de diciembre de 2020.

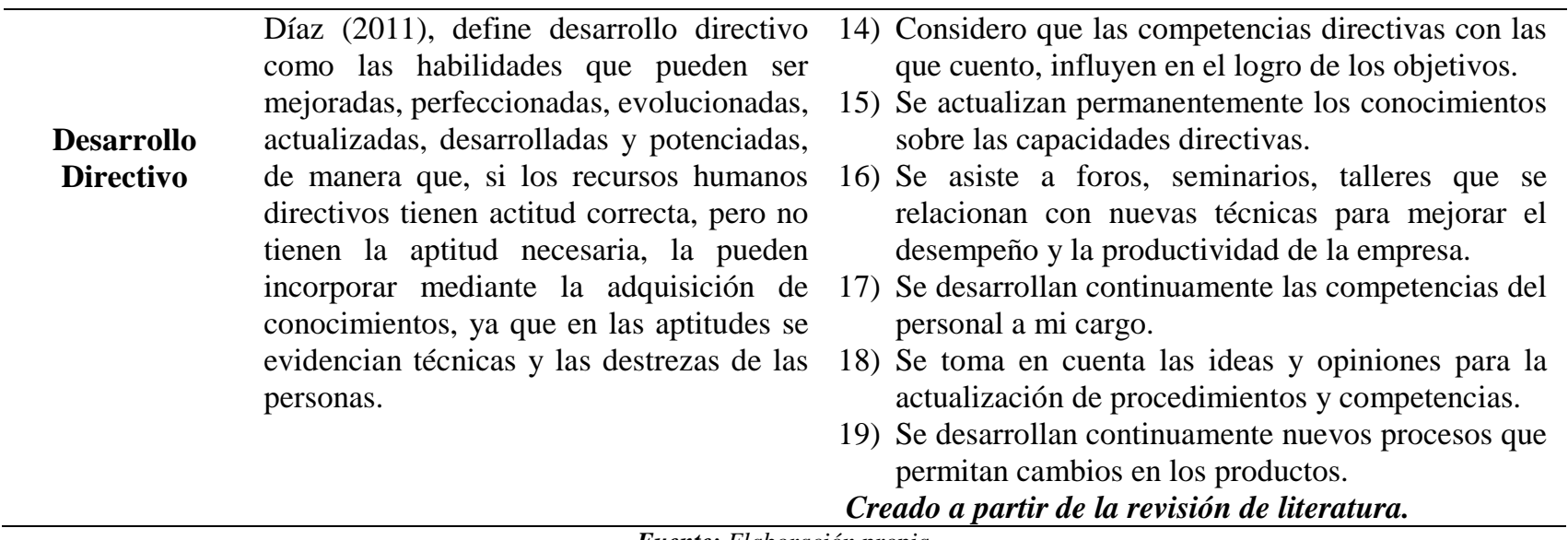

Fuente: Elaboración propia.

\section{Elaboración de instrumentos de medición.}

El instrumento consiste en un cuestionario conformado por 17 ítems derivado de la revisión de literatura. Para efectos de la presente investigación y mayor confiabilidad del instrumento, se realizó una prueba piloto con la aplicación de 50 encuestas con gerentes al azar de otra población no involucrada en el estudio final. En la etapa de capturar y procesar los datos para calcular la regresión lineal múltiple se utilizó el software SPSS, versión 21, el cual arrojó indicadores aceptables que permitieron constatar que el instrumento permitía medir las variables.

El instrumento de medición quedó conformado por dos partes, la primera parte corresponde a los datos generales y demográficos del entrevistado, entre aspectos tales como; antigüedad en la empresa, el puesto que le corresponde, género, escolaridad, edad, antigüedad de la empresa y el número de empleados con el que labora la organización. Con lo que respecta a la segunda parte, esta se construyó en base a la revisión de la literatura donde se destacan por segmentos las variables independientes denominadas habilidades del capital humano y la dependiente de la investigación que corresponde al Desarrollo directivo. 
"Fl sibler ite mis hijise

Año 13.

Núm. 33

https://revistainvestigacionacademicasinfrontera.unison.mx/index.php/RDIASF
Revista de Investigación

Académica sin Frontera

ISSN: 2007-8870

Recibido el 27 de mayo de 2020. Dictaminado mediante arbitraje favorablemente 22 de diciembre de 2020.

Para medir lo expresado por los entrevistados, se utilizó la escala de Likert basada en cinco puntos. 1: En total desacuerdo; 2: En desacuerdo; 3: Ni de acuerdo ni en desacuerdo; 4: De acuerdo; 5: Totalmente de acuerdo, se tomó este tipo de escala para no dejar un punto intermedio que en gran medida pudiera ocasionar la subjetividad.

\section{Captura y manual de codificación.}

La captura de los datos se hizo de manera manual, ingresando mencionados datos al sistema de software SPSS, versión 21, y se codificó de acuerdo a las necesidades del estudio para determinar los diferentes indicadores estadísticos que puedan servir para establecer conclusiones y recomendaciones de la investigación.

\section{Resultados}

\section{Confiabilidad y prueba piloto de instrumento.}

El instrumento de medición se puso a prueba mediante un piloto con 50 encuestas que se les fueron aplicadas a gerentes de restaurantes pertenecientes al municipio de Benito Juárez y las comunidades aledañas, posteriormente se aplicó un análisis factorial para validar el constructo y la confiabilidad del instrumento. Este análisis se ejecutó a través del índice de alfa de Cronbach, el cual mide la consistencia interna de cada constructo, de donde no se eliminaron ítems puesto que su confiabilidad fue aceptable como se muestra en la Tabla 4 del análisis de fiabilidad.

Como se muestra en respectiva tabla, todos los indicadores fueron satisfactorios, aunque solo fue uno el que estuvo por encima del promedio aceptado para el alfa de Cronbach, el cual debe de estar por arriba de 0.700 , y los dos constructos restantes estuvieron por encima del 0.665 pero 
"Fl suber ise mis hijisa

Año 13.

Núm. 33

https://revistainvestigacionacademicasinfrontera.unison.mx/index.php/RDIASF
Revista de Investigación

Académica sin Frontera

ISSN: 2007-8870

Recibido el 27 de mayo de 2020. Dictaminado mediante arbitraje favorablemente 22 de diciembre de 2020.

que no alcanzaron respectiva puntuación, lo que no es malo, puesto que se consideran relativamente aceptables.

De acuerdo con Celina y Campo (2005) citados por Bojórquez, Hernández, López y Jiménez (2013), el valor mínimo aceptable para el coeficiente alfa de Cronbach es 0.700; por debajo de ese valor la consistencia interna de la escala utilizada es baja. Este valor manifiesta la consistencia interna, es decir, muestra la correlación entre cada una de las preguntas; un valor superior a 0.700 revela una fuerte relación entre las preguntas, un valor inferior revela una débil relación entre ellas.

No es común, pero el alfa de Cronbach puede arrojar un valor negativo, esto indica un error en el cálculo o una inconsistencia de la escala. Por otra parte, hay autores como Lucero y Meza (2002) que mencionan que el valor mínimo aceptable del coeficiente de fiabilidad depende de la utilización que se hará del instrumento. Es decir, dependiendo de la exactitud requerida por la disciplina que lo requiere.

Como criterio general, George y Mallery (2003) citados por Frías (2019) sugieren las recomendaciones siguientes para evaluar los valores de los coeficientes de alfa de Cronbach:

- Coeficiente alfa $>.900$ a .950 es excelente

- Coeficiente alfa $>.800$ es bueno

- Coeficiente alfa >.700 es aceptable

- Coeficiente alfa >.600 es cuestionable

- Coeficiente alfa $>.500$ es pobre

- Coeficiente alfa <.500 es inaceptable 
nFl siber ite mis hijise

Año 13.

Núm. 33

https://revistainvestigacionacademicasinfrontera.unison.mx/index.php/RDIASF

Revista de Investigación

Académica sin Frontera

ISSN: 2007-8870

Recibido el 27 de mayo de 2020. Dictaminado mediante arbitraje favorablemente 22 de diciembre de 2020.

Tabla 4. Análisis de fiabilidad de la prueba piloto.

\begin{tabular}{lcc}
\hline \multicolumn{1}{c}{ Variable } & Alfa de Cronbach & Número de elementos \\
\hline $\mathrm{X}_{1}=$ Competencias directivas & 0.703 & 7 \\
$\mathrm{X}_{2}=$ Diversidad & 0.666 & 6 \\
$\mathrm{Y}=$ Desarrollo directivo & 0.683 & 6 \\
\hline \multicolumn{2}{c}{ Fuente: Elaboración propia a partir de los datos obtenidos en el SPSS v.21 }
\end{tabular}

\section{Análisis estadístico de regresión de la prueba piloto.}

La siguiente fórmula, representa de forma general el análisis estadístico del modelo de regresión múltiple, el cual indica la dependencia lineal de la variable de respuesta.

$\mathbf{Y}=\boldsymbol{\beta}_{0}+\boldsymbol{\beta}_{1} \mathbf{X}_{1}+\boldsymbol{\beta}_{2} \mathbf{X}_{2} \varepsilon$

Dónde:

$\mathrm{Y}=$ Desarrollo directivo

$\mathrm{B}_{0}=$ Constante del modelo

$\beta_{1} \ldots \beta_{5}=$ Betas del modelo

$\mathrm{X}_{1}=$ Competencias directivas

$\mathrm{X}_{2}=$ Diversidad

$\varepsilon=$ Error o variable aleatoria.

Se realizó una regresión múltiple con las variables independientes en relación a la dependiente, proceso que generó un modelo, donde esté obtuvo una $\mathrm{R}^{2}$ de 0.347 , constituido por la variable $\mathrm{X}_{1}=$ Competencias directivas, como se muestra en la Tabla siguiente, la cual resulta prácticamente en el límite de lo satisfactorio y quiere decir que sí las PyMEs le apuestan a las Competencias directivas van a tener un $34.7 \%$ de probabilidades de tener éxito en su Desarrollo directivo. 
"Fl suler ide mis hiipses hard mi pronderis

Año 13.

Núm. 33

https://revistainvestigacionacademicasinfrontera.unison.mx/index.php/RDIASF

Revista de Investigación

Académica sin Frontera

ISSN: 2007-8870

Recibido el 27 de mayo de 2020. Dictaminado mediante arbitraje favorablemente 22 de diciembre de 2020.

El estadístico de Durbin-Watson fue igual a 1.708, lo que permite asumir independencia entre los residuos, es decir no existe autocorrelación positiva o negativa entre los residuos, ya que está en el rango mayor a 1.5 y menor a 2.5 (Hanke y Wichern, 2006).

Tabla 5. Resultado del modelo de regresión múltiple de la prueba piloto.

\begin{tabular}{|c|c|c|c|c|c|c|c|c|c|}
\hline \multirow[b]{2}{*}{ Modelo } & \multirow[b]{2}{*}{$\mathbf{R}$} & \multirow[b]{2}{*}{$\mathbf{R}^{2}$} & \multirow[b]{2}{*}{$\begin{array}{c}\mathbf{R}^{2} \\
\text { corregida }\end{array}$} & \multirow[b]{2}{*}{$\begin{array}{l}\text { Error típ. de la } \\
\text { estimación }\end{array}$} & \multicolumn{4}{|c|}{ Estadísticos de cambio } & \multirow[b]{2}{*}{$\begin{array}{l}\text { Durbin- } \\
\text { Watson }\end{array}$} \\
\hline & & & & & $\begin{array}{c}\text { Cambio } \\
\text { en } \mathbf{R}^{2}\end{array}$ & $\begin{array}{c}\text { Cambio } \mathrm{gl}^{1} \\
\text { en } \mathrm{F}\end{array}$ & $\mathrm{gl}^{2}$ & $\begin{array}{l}\text { Sig. Cambio } \\
\text { en } F\end{array}$ & \\
\hline 1 & .589 & .347 & .333 & .605 & .347 & $25.476 \quad 1$ & 48 & .000 & 1.708 \\
\hline
\end{tabular}

La Tabla 6, muestra los coeficientes del modelo realizado por el método de pasos sucesivos donde los coeficientes no estandarizados contienen los coeficientes de regresión que definen la ecuación de regresión en puntuaciones directas. En esta tabla se muestra el modelo generado, el cual se encuentra compuesto por la variable independiente de $\mathrm{X}_{1}=$ Competencias directivas, con un valor absoluto en su coeficiente estandarizado Beta $(\beta)$ de 0.589 .

Tabla 6. Coeficientes de regresión de la prueba piloto (por pasos sucesivos).

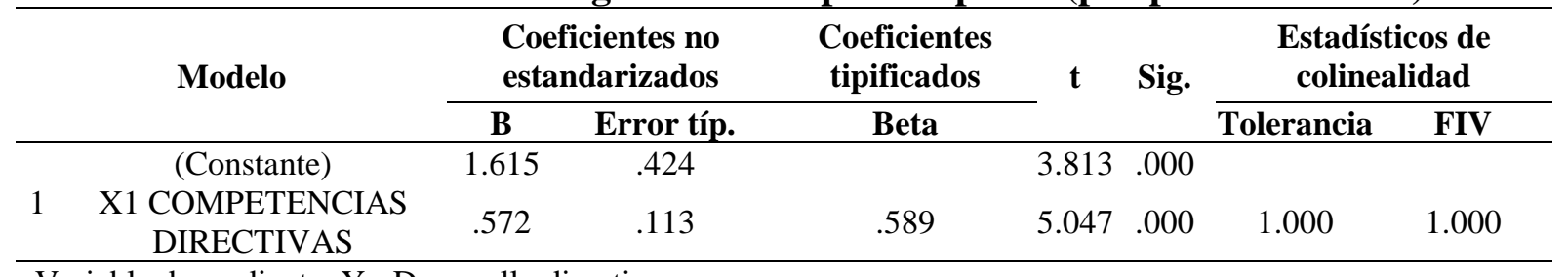

Variable dependiente: $\mathrm{Y}=$ Desarrollo directivo

Fuente: Elaboración propia a partir de los datos obtenidos en el SPSS v.21.

Las puntuaciones t mayor a 2.14, para los coeficientes del modelo de regresión, demuestran que la variable que aportan significancia al propio modelo es la variable $\mathrm{X}_{1}=$ Competencias directivas. El valor del factor de inflación de la varianza (FIV) es menor a 10 y muy cercanos a 1; 
"Fl sibler ite mis hijise

Año 13.

Núm. 33

https://revistainvestigacionacademicasinfrontera.unison.mx/index.php/RDIASF
Revista de Investigación

Académica sin Frontera

ISSN: 2007-8870

Recibido el 27 de mayo de 2020. Dictaminado mediante arbitraje favorablemente 22 de diciembre de 2020.

es decir, que resultó valor para $\mathrm{X}_{1}=$ Competencias directivas, con 1.000 como se ve en la Tabla, mientras que el valor de tolerancia $(\mathrm{T})$ fue mayor a 0.10 .

Con base a todos los supuestos anteriores y cumpliéndose cada uno de ellos, se determinó la función de regresión lineal óptima, partiendo del regresor $\mathrm{X}_{1}=$ Competencias administrativas el cual fue significativo en $\mathrm{p}$ (valor) < 0.05, tal y como se mostró en la Tabla anterior y en la siguiente fórmula, lo que indica que dicha variable contribuye de forma significativa a explicar lo que ocurre con la variable dependiente. A continuación, se muestra la ecuación de regresión:

$\mathbf{Y}=\boldsymbol{\beta}_{0}+\boldsymbol{\beta}_{1} \mathbf{X}_{1}+\varepsilon$

Desarrollo directivo $(\mathrm{Y})=1.615+0.572 *\left(\mathrm{X}_{1}=\right.$ Competencias directivas $)$

\section{Discusión}

Este estudio se focalizó en medir la incidencia positiva que existe entre la variable dependiente definida como $\mathrm{Y}=$ Desarrollo directivo y las variables independientes $\mathrm{X}_{1}=$ Competencias directivas y $\mathrm{X}_{2}=$ Diversidad, denominadas habilidades del capital humano de las PyMEs del giro restaurantes ubicadas en Ciudad Obregón, Sonora, México.

La investigación genero una hipótesis que consiste en determinar si es confiable el instrumento que mide las habilidades del capital humano con relación a las variables de Competencias directivas, la Diversidad y Desarrollo de los directivos de las PyMEs del giro restaurantes ubicadas en ciudad Obregón, Sonora, México.

Por lo anterior se puede asumir que la hipótesis planteada es aceptada puesto que los coeficientes de regresión del modelo realizado por el método de pasos sucesivos definieron un valor absoluto satisfactorio en su coeficiente estandarizado Beta $(\beta)$ de 0.589 demostrando así, una relación entre la Variable independiente Competencias directivas y la Variable dependiente Desarrollo directivo. 
"Fl silwer ile mis hijics

Año 13.

Núm. 33

https://revistainvestigacionacademicasinfrontera.unison.mx/index.php/RDIASF
Revista de Investigación

Académica sin Frontera

ISSN: 2007-8870

Recibido el 27 de mayo de 2020. Dictaminado mediante arbitraje favorablemente 22 de diciembre de 2020.

El resultado de la puntuación $\mathrm{t}$ fue satisfactorio con 5.047 mayor a 2.14, el valor del factor de inflación de la varianza (FIV) fue de 1.000 donde el indicador determina que debe ser menor a 10 y muy cercano a 1 mientras que, el valor de tolerancia (T) fue de 1.000 sobrepasando el indicador que establece que debe ser mayor a 0.10 .

Por lo tanto, basado en los resultados de esta prueba piloto se puede recomendar a los empresarios de las PyMEs que se les aplico el cuestionario, que le apuesten a la variable independiente diversidad, que la utilicen de manera positiva en sus organizaciones, puesto que, el tener un equipo de trabajo conformado por personas de géneros distintos, con capacidades atípicas, de culturas y creencias diferentes brinda una visión más amplia en cuanto a la resolución de situaciones y problemas, teniendo diversas ideas y formas de pensar para la toma de decisiones. Así mismo, la diversidad incrementara la creatividad y la innovación de sus empresas y fomentara por supuesto un ambiente laboral más equitativo.

\section{Conclusión}

Como conclusión del presente estudio se puede asumir que, a partir del análisis de los resultados obtenidos, se observó que el cuestionario logró cumplir su objetivo, mismo que consistía en determinar el grado de vinculación entre el desarrollo directivo y las habilidades del capital humano, el cual se logró midiendo el grado de confiabilidad del cuestionario mediante el indicador de las Alfa de Cronbach obteniendo resultados positivos.

También se observó un comportamiento adecuado del instrumento a la hora de aplicarlo a los directivos seleccionados. Dicho cuestionario generó un modelo, donde esté obtuvo una $\mathrm{R}^{2}$ de 0.347, constituido por la variable $\mathrm{X}_{1}=$ Competencias directivas, donde prácticamente resulto satisfactorio debido a que si las PyMEs invierten en que sus gerentes obtengan Competencias 
Año 13.

Núm. 33

ISSN: 2007-8870

https://revistainvestigacionacademicasinfrontera.unison.mx/index.php/RDIASF

Recibido el 27 de mayo de 2020. Dictaminado mediante arbitraje favorablemente 22 de diciembre de 2020.

directivas con diferentes estrategias van a tener un $34.7 \%$ de probabilidades de tener éxito en su $\mathrm{Y}=$ Desarrollo directivo.

Por lo antes mencionado, es de suma importancia que los altos mandos entiendan y tomen conciencia que tanto, el desarrollar competencias como: visión de negocio, resolución de problemas, trabajo en equipo, negociación, comunicación, delegación, autocontrol entre otras, y el que en las empresas exista un proceso de inclusión de personas son aspectos que les permitirán gestionar de manera efectiva los recursos con los que disponen tanto humanos como materiales para crecer profesionalmente, y a su vez, incrementar la productividad y las utilidades de las empresas.

En este sentido, con el fortalecimiento óptimo de esta variable denominada Desarrollo directivo se podría detonar la productividad de las empresas y se tendrían entonces oportunidades de mejora en los siguientes aspectos como planear estratégicamente, utilizar nueva tecnología, formar equipos de trabajo eficaces, adquirir conocimientos y habilidades para desempeñar diferentes funciones dentro de la entidad, analizar el desempeño laboral de sus colaboradores para el logro de las metas de la empresa, desarrollar las capacidades requeridas por su puesto mediante capacitaciones, que podría dar como resultado mejores directivos preparados para enfrentar nuevos retos que el futuro tan incierto que les depare. Siendo estos, los principales protagonistas en la orientación de las empresas, capaces de llevarlas el éxito o al fracaso.

En las investigaciones futuras una posible y conveniente línea de trabajo podrían ser, la de replicar el presente estudio en pequeñas y medianas empresas de otro sector económico de Ciudad Obregón, como también podría llevarse a cabo en otros municipios de Sonora o de estados diferentes del país. Por otro lado, parece factible desarrollar el estudio agregando más variables independientes, como visión de negocio, resolución de problemas, trabajo en equipo, negociación, comunicación, delegación y autocontrol. Por último, otra interesante línea de trabajo podría ser el 
"Fl suler ide mis hiipses

Año 13.

Núm. 33
Revista de Investigación

Académica sin Frontera

ISSN: 2007-8870

https://revistainvestigacionacademicasinfrontera.unison.mx/index.php/RDIASF

Recibido el 27 de mayo de 2020. Dictaminado mediante arbitraje favorablemente 22 de diciembre de 2020.

remplazar la variable dependiente por alguna otra, como; clima organizacional o competitividad empresarial.

\section{Referencias}

Amorós E. (2007). Comportamiento organizacional en busca del desarrollo de ventajas competitivas. Recuperado el día 12 de julio de 2020 de https://www.academia.edu/10362382/comportamiento_organizacional_en_busca_del_des arrolo_de_ventajas_competitivas.

Anapan, L. (2018). Habilidades gerenciales y desarrollo organizacional de los médicos jefes en los establecimientos de salud de la ex Red Túpac Amaru, Lima. Recuperado de http://repositorio.ucv.edu.pe/bitstream/handle/UCV/30565/Anapan_BLE.PDF?SEQUEN $\mathrm{CE}=1$ \&isAllowed $=\mathrm{y}$.

Apóyala, M. (2012). Operalización de las variables. Recuperado de http://bvsper.paho.org/videosdigitales/matedu/2012investigacionsalud/201206260peracio nalizacion_MoisesApolaya.pdf?ua=1.

Ávila, H. (2014). Las PYMES en México: desarrollo y competitividad. Observatorio de la Economía Latinoamericana, 201.

Bojórquez, A., Hernández, M, Jiménez, E. y López, L. (2013). Utilización del alfa de Cronbach para validar la confiabilidad de un instrumento de medición de satisfacción del estudiante en el uso del software Minitab. Recuperado de http://laccei.org/LACCEI2013Cancun/RefereedPapers/RP065.pdf.

Cámara Nacional de la Industria de Restaurantes y Alimentos Condimentados (CANIRAC). (2011). Industria Restaurantera en México. Recuperado de http://www.canirac.org.mx/pdf/canirac-20110713-cifras-del-sector-restaurantero.pdf.

Cardozo, E., De Naime, V. \& Monroy, C. (2012). El concepto y la clasificación de pyme en América Latina. ISSN 1931-0285 CD ISSN 1941-9589 ONLINE, 1657.

Celina H. \& Campo A. (2005). “Aproximación al uso del coeficiente alfa de Cronbach”, Revista colombiana de psiquiatría, vol. XXXIV, número 004, Asociación Colombiana de Psiquiatría, Bogotá, Colombia, pp. $572-580$, disponible en: http://redalyc.uaemex.mx/pdf/806/80634409.pdf.

Chiavenato, I. (2011). Administración de recursos humanos. El capital humano de las organizaciones (9a ed.). México, D.F.: McGraw-Hill Interamericana Editores, S.A. 
"Fl suler ide mis hiipses

Año 13.

Núm. 33
Revista de Investigación

Académica sin Frontera

ISSN: 2007-8870

https://revistainvestigacionacademicasinfrontera.unison.mx/index.php/RDIASF

Recibido el 27 de mayo de 2020. Dictaminado mediante arbitraje favorablemente 22 de diciembre de 2020.

Chinchilla, N., \& Cruz, H. (2011). Diversidad y paradigmas de empresa: un nuevo enfoque. Empresa y Humanismo, 14(1).

Chinchilla, N., \& García, P. (2001). Estudio sobre competencias directivas. Recuperado de http://C:/Users/User/Desktop/Articulo\%20Competencias\%20directivas\%20(1).pdf.

Comisión Económica para América Latina y el Caribe (CEPAL). (2009). Manual de la Micro, Pequeña y Mediana Empresa. Recuperado de http://www.cepal.org/es/publicaciones/2022manual-la-micro-pequena-mediana-empresa-contribucion-la-mejora-sistemas.

Cuervo, A. (2004). Introducción a la empresa: funciones directivas. 1recuperado de http://josejavierfernandez.weebly.com/uploads/2/6/6/7/2667447/temavi.funciones_directi vas.pdf.

De Haro, J. (2011). Desarrollo directivo, directivos en desarrollo. Recuperado de http://www.researchgate.net/publication/257921724_DESARROLLO_DIRECTIVO_DIR ECTIVOS_EN_DESARROLLO.

Díaz, C. (2017). PyMEs en Sonora. Recuperado de http://proyectopuente.com.mx/2017/05/04/60las-pymes-en-sonora-cierran-a-los-dos-anos-economia/.

Díaz, R. (2011). Enfoque de las Competencias Laborales: Historia, Definiciones y Generación de un Modelo de Competencias para las Organizaciones y las personas. Pág. 211.

Diccionario empresarial. (2008). Desarrollo directivo. Recuperado de http://diccionarioempresarial.wolterskluwer.es/Content/Documento.aspx?params=H4sIA AAAAAAEAMtMSbF1jTAAASNjIyMjtbLUouLM_DxbIwMDS0NDA1OQQGZapUtckhlQaptWmJOcSoAg03jYjUAAAA=WKE.

Elizondo, M., Armenteros, M. \& Molina, V. (2014). Competencias directivas para PyMe: una evaluación diagnóstica en el sector servicios en Saltillo Coahuila. Revista internacional administración y finanzas, volumen 7, número 7. Recuperado de http://C:/Users/User/Desktop/SSRN-id2499676.pdf.

Estrada, R., García, D. \& Sánchez, V. (2009). Factores determinantes del éxito competitivo en la Pyme: Estudio Empírico en México.

Estrella, A., Jiménez, L. Ruiz, J. \& Sánchez, M. (2012). ¿Cómo compiten las pymes en los mercados internacionales? Análisis de un clúster local con vocación exportadora. Investigaciones europeas de Dirección y Economía de la Empresa, 18(1), 87-99.

Forbes Adventorial. (2018). Diversidad e inclusión laboral, un factor de éxito en los negocios. Recuperado de https://www.forbes.com.mx/diversidad-e-inclusion-laboral-un-factor-deexito-en-los-negocios/

Forbes. (2018). Pymes Mexicanas un panorama para 2018. Recuperado de http://www.forbes.com.mx/pymes-mexicanas-un-panorama-para-2018/. 
Recibido el 27 de mayo de 2020. Dictaminado mediante arbitraje favorablemente 22 de diciembre de 2020.

Frías, D. (2019). Apuntes de consistencia interna de las puntuaciones de un instrumento de medida. Universidad de Valencia. España. Disponible en: https://www.uv.es/friasnav/AlfaCronbach.pdf.

George, D., \& Mallery, P. (2003). SPSS for Windows step by step: A simple guide and reference. 11.0 update (4thed.). Boston: Allyn \& Bacon.

Gill, M. (2009). Como crear y hacer funcionar una empresa. Madrid. Editorial; ESIC. Libro $\begin{array}{lllllll}\text { recuperado el } & 16 & \text { de } & \text { febrero } & \text { de }\end{array}$ http://books.google.com.mx/books?id=4O2e7DjTQL4C\&pg=PA15\&dq=que+es+una+em presa\&hl=es\&sa=X\&ved=0ahUKEwjz1OWnlMfgAhWpIjQIHbCXAsMQ6AEINjAC\#v= onepage \&q=que $\% 20$ es $\% 20$ una $\% 20$ empresa $\& \mathrm{f}=$ false.

Hanke, J., \& Wichern, D. (2006). Pronósticos en os negocios. México. Pearson educación.

Hernández, R. (2014). Metodología de la investigación sexta edición. Recuperado de http://observatorio.epacartagena.gov.co/wp-content/uploads/2017/08/metodologia-de-lainvestigacion-sexta-edicion.compressed.pdf.

INEGI. (2019). Clasificación para actividades económicas. Recuperado de file:///C:/Users/User/Desktop/Clasificacion_act_econENOE\%20(1).pdf.

Instituto Tecnológico y de Estudios Superiores de Monterrey. (2009). Liderazgo, calidad y competencias directivas. Recuperado de http://cca.org.mx/profesores/cursos/ed129/html/m03/apoyos/modulo3vi.pdf

Ley para el Desarrollo de la competitividad de la Micro, Pequeña y Mediana Empresa. (2019). Recuperado de http://www.diputados.gob.mx/LeyesBiblio/pdf/247_130819.pdf.

Leyva, A., Cavazos, J. \& Espejel, J. (2018). Influencia de la planeación estratégica y habilidades gerenciales como factores internos de la competitividad empresarial de las PyMEs. Recuperado de http://www.scielo.org.mx/pdf/cya/v63n3/0186-1042-cya-63-03-00003.pdf.

López, A. \& Molina, R. (2014). El emprendimiento y crecimiento de las Pymes. Recuperado de http://www.redalyc.org/pdf/416/41648308006.pdf

López, R. (2017). El desarrollo gerencial del talento humano directivo de la empresa Caja Los Andes-2017.

Lorenzana, D. (2020). Las 6 habilidades que debe poseer un buen líder gerencial. Recuperado de http://www.emprendepyme.net/las-habilidades-gerenciales.html.

Lucero I. \& Meza S. (2012). Validación de instrumentos para medir conocimientos. Recuperado de http://www1.unne.edu.ar/cyt/2002/09-Educacion/D-027.pdf.

Mapa de México. Recuperado de https://compromisoporlaeducacion.mx/consejo-estatal-desonora/.

Mertens, L. (2001). Competencia Laboral: Sistemas, surgimiento y modelos. Editorial Narcea. Madrid. 
Recibido el 27 de mayo de 2020. Dictaminado mediante arbitraje favorablemente 22 de diciembre de 2020.

ONU. (2018). PyMEs: la espina dorsal de la economía mundial. Recuperado de https://www.20minutos.es/noticia/3382959/0/pymes-microempresas-onu-economiaempleo/.

Organización Internacional del Trabajo (OIT). (2019). La mayor parte del empleo mundial procede de las pequeñas empresas y los trabajadores independientes, concluye un nuevo informe de la OIT. Recuperado de http://www.ilo.org/global/about-theilo/newsroom/news/WCMS 723414/lang--es/index.htm.

Patrón, R. \& Barroso, F. (2015). Competencias directivas de gerentes de restaurantes turísticos. Estudios y perspectivas en turismo volumen 24. Recuperado de http://www.redalyc.org/pdf/1807/180732864006.pdf.

Peña, E. (2015). La motivación laboral como herramientas de gestión en las organizaciones empresariales. Recuperado

de http://repositorio.comillas.edu/xmlui/bitstream/handle/11531/4152/TFG001138.pdf?seque nce $=1$.

Pereda, F. (2016). Análisis de las habilidades directivas. estudio aplicado al sector público de la provincia. Recuperado de https://helvia.uco.es/xmlui/handle/10396/13398.

Pérez, F. \& Serrano, L. (2013). Capital humano y formación de directivos: situación española y estrategias de mejora. Economía industrial, 387(1), 87-107.

Puga, J. \& Martínez L. (2008). Competencias directivas en escenarios globales. Recuperado de: http://C:/Users/User/Documents/ANA/LAE\%20VIII/TESIS/Articulos\%20de\%20mi\%20t esis/Competencias\%20directivas\%20en\%20escenarios\%20globales.pdf.

Ramírez G. (2016). Informe de Gestión Directiva. Recuperado de https://www.planeacion.unam.mx/informes/PDF/CCHV-2016.pdf.

Ramírez J., Cerón, H., Cerón, A. \& Maya, N. (2017). Las competencias directivas base de la competitividad empresarial: Un estudio correlacional. Revista administración y finanzas Vol.4 No.12 87-98. $\quad$ Recuperado de http://C:/Users/User/Desktop/Revista_de\%20_Administraci\%C3\%B3n_y_Finanzas_V4_ N12_7\%20(1).pdf.

Secretaría de Economía de Sonora. (2019). Crecimiento de las MiPyMEs. Recuperado de http://economiasonora.gob.mx/portal/prensa/noticias/601-fomenta-secretaria-deeconomia-crecimiento-de-las-mipymes.

Serrano, G. (2017). Competencias directivas y virtudes. Recuperado de https://www.sciencedirect.com/science/article/pii/S0123592317300268.

Torres, C. (2017). Las organizaciones han reconocido la necesidad de gestionar intangibles. Recuperado de https://www.coursehero.com/file/p62llgq/Las-organizaciones-hanreconocido-la-necesidad-de-gestionar-intangibles-asegura/ 


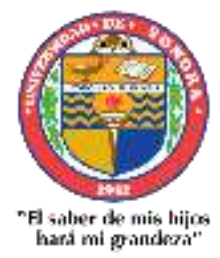

( Julio - Diciembre 2020)

Año 13.

Revista de Investigación

Núm. 33

Académica sin Frontera

ISSN: 2007-8870

https://revistainvestigacionacademicasinfrontera.unison.mx/index.php/RDIASF

Recibido el 27 de mayo de 2020. Dictaminado mediante arbitraje favorablemente 22 de diciembre de 2020.

Torres, V., Wendlandt A. \& López, M. (2016). La Formalización Administrativa De La Pequeña Y Mediana Empresa Industrial Alimentaria De Ciudad Obregón, Sonora, México (The Administrative Formalization of the Small and Medium-Sized Enterprise of the Food Industry from Ciudad Obregón, Sonora, México). Revista Global de Negocios, 4(2), 33-44.

Universia Colombia. (2017). La importancia de la inclusión y la diversidad en el mundo laboral. Recuperado de https://noticias.universia.net.co/enportada/noticia/2013/10/01/1053212/importancia-inclusion-diversidad-mundolaboral.html.

Valencia, M. (2005). El capital humano, otro activo de su empresa. Recuperado de https://www.redalyc.org/pdf/2654/265420471004.pdf. 
Año 13.

Académica sin Frontera

Núm. 33

ISSN: 2007-8870

https://revistainvestigacionacademicasinfrontera.unison.mx/index.php/RDIASF

Recibido el 27 de mayo de 2020. Dictaminado mediante arbitraje favorablemente 22 de diciembre de 2020.

\section{Directorio Institucional}

Dr. Enrique Fernando Velázquez Contreras

Rector

Dr. Ramón Enrique Robles Zepeda

Secretario General Académico

Dra. Rosa María Montesinos Cisneros

Secretaria General Administrativa

Dr. Rodolfo Basurto Álvarez

Director de Vinculación y Difusión

Dra. Adriana Leticia Navarro Verdugo

Vicerrectora de la Unidad Regional Sur

Dr. Ernesto Clark Valenzuela

Director de la División de Ciencias Económicas y Sociales

Dr. Francisco Espinoza Morales

Secretario de la División de Ciencias Económico y Sociales

Dra. Leticia María González Velásquez

Jefe del Departamento de Ciencias Económico Administrativas

Dra. Lidia Amalia Zallas Esquer

Jefe de Departamento de Ciencias Sociales 
"Fl suler ide mis hiipses

Año 13.

Núm. 33

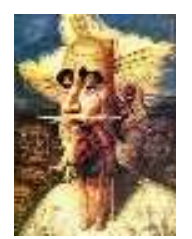

Revista de Investigación

Académica sin Frontera

ISSN: 2007-8870

https://revistainvestigacionacademicasinfrontera.unison.mx/index.php/RDIASF

Recibido el 27 de mayo de 2020. Dictaminado mediante arbitraje favorablemente 22 de diciembre de 2020.

\title{
Comité Directivo
}

\author{
Editor Responsable \\ Dr. Francisco Espinoza Morales \\ Universidad de Sonora \\ Directora \\ Dra. Leticia María González Velásquez \\ Universidad de Sonora \\ Subdirector \\ Dr. Javier Carreón Guillen \\ Universidad Nacional Autónoma de México \\ Editor Científico \\ Dr. Cruz García Lirios \\ Universidad Autónoma del estado de México \\ Master Gráfico \\ M.T.I. Francisco Alan Espinoza Zallas \\ Universidad Estatal de Sonora
}

Nos complace anunciar que su diario, "Academic Research Journal Withoutborders" (ISSN/EISSN 20078870) fue evaluado positivamente en la indexación Citefactor, ahora la página de la revista está disponible en línea, en caso de cualquier problema.

Journals Master | International Innovative Journal Impact Factor (IIJIF)

Red Latinoamericana de revistas Académicas en Ciencias Sociales y Humanidades
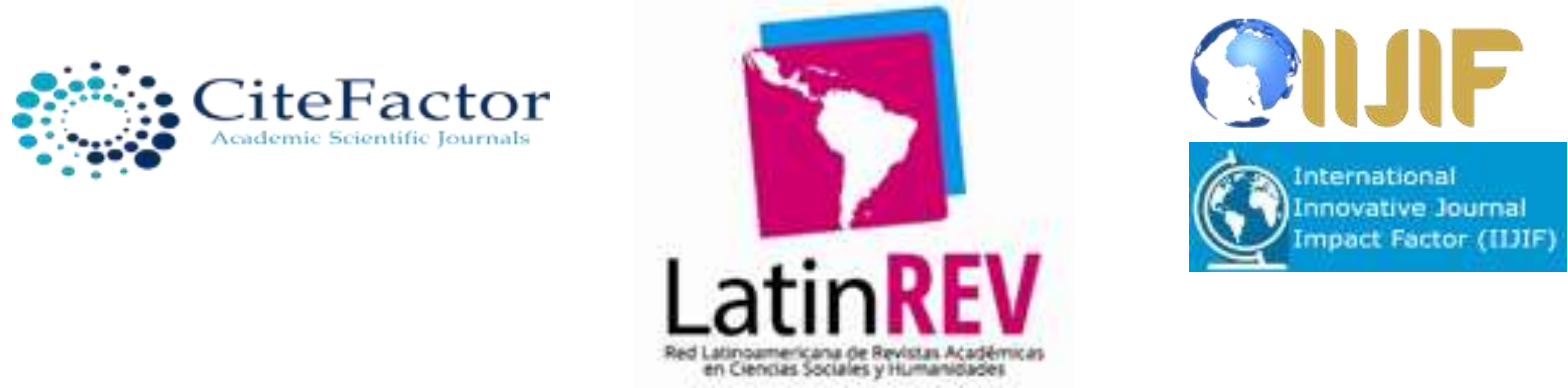
Año 13.

Académica sin Frontera

Núm. 33

ISSN: 2007-8870

https://revistainvestigacionacademicasinfrontera.unison.mx/index.php/RDIASF

Recibido el 27 de mayo de 2020. Dictaminado mediante arbitraje favorablemente 22 de diciembre de 2020.

\section{Comité editorial}

Dra. Angélica María Rascón Larios

Universidad de Sonora. México

Dra. María del Rosario Molina González

Universidad de Sonora

Dra. Francisca Elena Rochin Wong

Universidad de Sonora. México

Dra. Lidia Amalia Zallas Esquer

Universidad de Sonora. México

Dra. Beatriz Llamas Arechiga

Universidad de Sonora. México

Dr. Rogelio Barba Álvarez

Universidad de Guadalajara. México

Dra. Rosa María Rincón Ornelas

Universidad de Sonora. México

Dr. Juan Flores Preciado

Universidad de Colima. México

Dr. Amado Olivares Leal. Universidad de Sonora

Universidad de Sonora. México

Dr. Guillermo Velázquez Valadez.

Instituto Politécnico Nacional (IPN) México

Dr. Hugo Nefstalí Padilla Torres.

Universidad Estatal de Sonora. México

Dr. Luis Ramón Moreno Moreno.

Universidad Autónoma de Baja California. México

Dr. Miguel Ángel Vázquez Ruiz.

Universidad de Sonora. México 
"Fl suler ide mis hiipses

Año 13.

Núm. 33

https://revistainvestigacionacademicasinfrontera.unison.mx/index.php/RDIASF
Revista de Investigación

Académica sin Frontera

ISSN: 2007-8870

Recibido el 27 de mayo de 2020. Dictaminado mediante arbitraje favorablemente 22 de diciembre de 2020.

Dra. Lorena Vélez García.

Universidad Autónoma de Baja California. México

Dra. Pabla Peralta Miranda.

Universidad Simón Bolívar, Barranquilla, Colombia

Mtro. Roberto Espíritu Olmos

Universidad de Colima (FCA Tecomán) Colima

Dr. Héctor Priego Huertas.

Universidad de Colima (FCA Tecomán) Colima

Mtra. María Guadalupe Alvarado Ibarra.

Universidad de Sonora. México.

MSc. Celso Germán Sánchez Zayas

Universidad de Camagüey, Ignacio Agramonte Loynaz, Cuba

Dra. María Luisa Quintero Soto

Universidad Autónoma del Estado de México

Dr. Eyder Bolivar Mojica

Universidad Católica, Luis Amigó, Medellin, Colombia

Revisores de Textos en Inglés

Mtro. Renato Encinas

Mtra. Cecilia Guadalupe Martínez Solano

\section{Comité científico}

Dr. Rosendo Martínez Jiménez. Universidad Autónoma Benito Juárez de Oaxaca.

Dr. Hugo Neftalí Padilla. Universidad Estatal de Sonora

Dra. María Teresa Gaxiola Sánchez. Universidad de Sonora.

Dr. José Cesar Kaplan. Universidad Estatal de Sonora.

Dr. Alfredo Islas Rodríguez. Universidad de Sonora

Frecuencia de publicación: semestral / 2 números por año. 


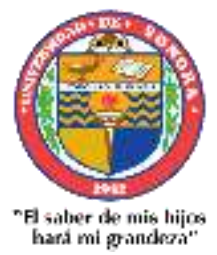

( Julio - Diciembre 2020)

Año 13.

Revista de Investigación

Núm. 33

Académica sin Frontera

ISSN: 2007-8870

https://revistainvestigacionacademicasinfrontera.unison.mx/index.php/RDIASF

Recibido el 27 de mayo de 2020. Dictaminado mediante arbitraje favorablemente 22 de diciembre de 2020.

Revista de Investigación Académica sin Frontera (RIASF) con (ISSN: 2007-8870) es un interlocutor internacional de acceso abierto revisado diario en línea en el ámbito del de las Ciencias Económicas Administrativas y Sociales. Su objetivo principal es dar a los trabajos de investigación de calidad. Cubre todas las sub-campos de los campos anteriormente mencionados. Proporciona la plataforma a académicos, estudiantes y profesionales. Sólo pública trabajos de investigación y artículos de revisión inicial. Documento presentado debe cumplir con algunos criterios como, debe ser original, inédita y no estén sometidos a ninguna otra revista. RIASF es una revista arbitrada / Revisión por pares International. Publicamos documentos sobre una variedad de temas, contextos y estrategias de análisis que examinan la relación entre la rápida evolución para la Sociedad y la tecnología del conocimiento.

REVISTA DE INVESTIGACIÓN ACADÉMICA SIN FRONTERA, Año 13, No. 33, Julio - diciembre 2020, es una publicación semestral de investigación científica, editada por la Universidad de Sonora, a través de las División de Ciencias Económicas y Sociales, de la Unidad Regional Sur, Blvd. Lázaro Cárdenas No. 100, Col. Francisco Villa, Navojoa, Sonora, Sonora, México, C.P. 85880. Tel. (642) 425- 99-54.

https://revistainvestigacionacademicasinfrontera.unison.mx/index.php/RDIASF

revistaacademicasinfrontera@unison.mx.

Editor responsable: Francisco Espinoza Morales. Reserva de Derechos al Uso Exclusivo: 04-2013121811323700-203 e ISSN: 2007-8870, ambos otorgados por el Instituto Nacional de Derecho de Autor. Inscrita en el Directorio de LATINDEX, con Núm. De folio 20014, folio único 14590. Responsable de la última actualización de este Número, Unidad Informática de la Universidad de Sonora, fecha de la última modificación, 30 de diciembre 2020, indexada a Cite Factor Academic Scientific Journal y Journals Master (IIJIF) y Red Latinoamericana de Revistas Académicas en Ciencias Sociales y Humanidades, (Latín Rev). Las opiniones expresadas por los autores no necesariamente reflejan la postura del editor de la publicación. Se autoriza la reproducción total o parcial de los contenidos e imágenes en la presente publicación siempre y cuando se cuente con la autorización del editor y se cite plenamente la fuente. 

"Fl suler ile mis hijos
harfi mi prondezi"

Año 13.

Núm. 33

https://revistainvestigacionacademicasinfrontera.unison.mx/index.php/RDIASF

Revista de Investigación

Académica sin Frontera

ISSN: 2007-8870

Recibido el 27 de mayo de 2020. Dictaminado mediante arbitraje favorablemente 22 de diciembre de 2020.

Nos complace anunciar que su diario, "Academic Research Journal Withoutborders" (ISSN/EISSN 20078870) fue evaluado positivamente en la indexación Citefactor, ahora la página de la revista está disponible en línea, en caso de cualquier problema.

Journals Master | International Innovative Journal Impact Factor (IIJIF)

\section{Red Latinoamericana de revistas Académicas en Ciencias Sociales y Humanidades}

CiteFactor

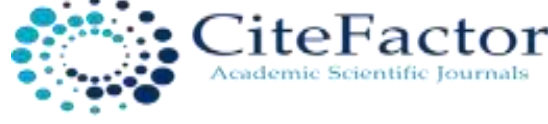

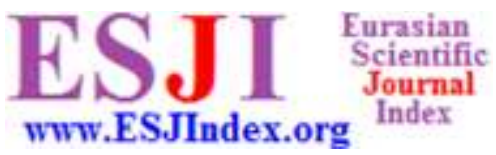

https://www.neliti.com

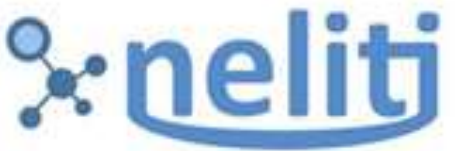

Indonesia's Research Repository
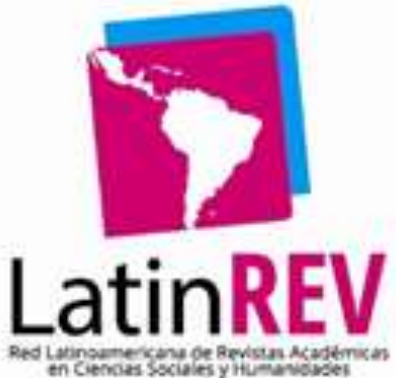
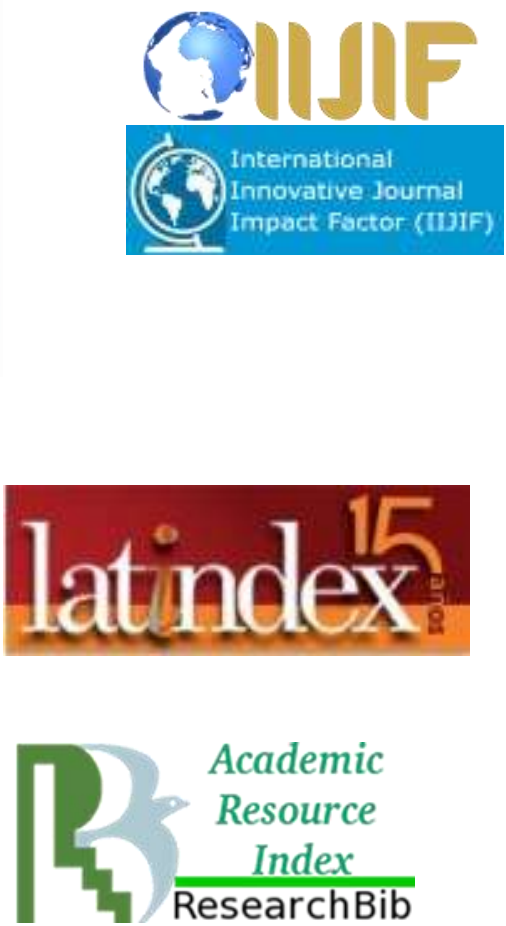

Academic

Resource

Index

ResearchBib 